\title{
BUDAYA ORGANISASI SATUAN POLISI PAMONG PRAJA (SATPOL PP) KOTA BANDUNG
}

\author{
Ismail Nurdin \\ Direktur IPDN Sumatera Barat dan Staf Pengajar Institut Pemerintahan Dalam Negeri \\ E-mail : ismailnurdin@gmail.com
}

\begin{abstract}
ABSTRAK. Budaya organisasi merupakan determinan utama dalam efektivitas pelaksanaan tugas satuan polisi pamong praja Kota Bandung. Penelitian ini dilakukan untuk mengetahui: 1) isi budaya, 2) kemampuan adaptasi lingkungan eksternal dan 3) keutuhan internal budaya organisasi. Penelitian dilakukan dengan menggunakan metode deskriptif-kualitatif. Sumber data diperoleh dari informan dengan teknik wawancara, observasi dan telaah dokumentasi. Hasil penelitian menunjukkan bahwa budaya organisasi belum kondusif karena belum mampu melakukan adaptasi terhadap perubahan lingkungan eksternal, seperti : belum dikembangkannya secara adaptif rumusan visi dan misi, tujuan organisasi, strategi organisasi, sarana prasarana, pengembangan pengukuran kinerja dan perbaikan kelembagaan. Belum efektifnya keutuhan integrasi internalnya, seperti : penguatan kebersamaan dan konsensus anggota, hubungan antar anggota, mekanisme penghargaan dan hukuman.
\end{abstract}

Kata kunci : budaya organisasi, eksternal adaptasi budaya, internal integrasi budaya

\section{CULTURAL ORGANIZATION CIVIL SERVICE POLICE UNIT (SATPOL PP) BANDUNG}

ABSTRACT. Organizational culture is a major determinant in the effectiveness of the task force police civil service Bandung. This study was conducted to determine the content of the cultural and environmental adaptability of external and internal integrity of the organization's culture. The study was conducted using a descriptive-qualitative method. Sources of data obtained from informants by interview, observation and review of documentation. The results showed that organizational culture is not conducive for not been able to adapt to changes in the external environment, such as: the development of an adaptive manner yet the vision and mission statement, organizational goals, organizational strategies, infrastructure, development and improvement of institutional performance measurement. The ineffectiveness of the integrity of internal integration, such as: the strengthening of unity and consensus of members, the relationship between members, the mechanism of reward and punishment.

Keywords: organizational culture, cultural adaptation eksternal, cultural integration internal

\section{PENDAHULUAN}

Ketika menyebut Polisi Pamong Praja, masyarakat khususnya pedagang kaki lima, anak jalanan, gepeng dan lainnya mengaitkan dengan "penggusuran" bahkan "kekerasan". Pada beberapa kejadian polisi pamong praja dalam pelaksanaan tugas sebagai perangkat pemerintahan daerah dalam fungsi ketentraman dan ketertiban umum seringkali mempraktekkan cara-cara refresif yang berujung pada terjadinya bentrok. Pada sisi lain anggota polisi pamong praja menganggap bahwa apa yang dilakukan adalah dalam rangka tuntutan pelaksanaan tugas, sesuai dengan kewenangan yang dimiliki sebagai perangkat pemerintahan daerah yakni kewenangan penciptaan ketentraman dan ketertiban umum.

Polisi Pamong Praja ibarat judul lagu "benci tapi rindu". Keberadannya seringkali dicaci dan dibenci tapi disisi lain ia diperlukan dalam menciptakan keteraturan, ketertiban dan kenyamanan masyarakat. Kelembagaan polisi pamong praja sudah merupakan bagian dari perangkat pemerintahan daerah dan keberadaanya strategis dalam penyelenggaraan pemerintahan daerah bukan saja dalam penciptaan ketentraman dan ketertiban umum tapi juga dalam rangka peneggakan peraturan daerah dan turut memberikan kontribusi peran dalam pelaksanaan kebijakan program dan kegiatan pemerintahan daerah.

Satuan Polisi Pamong Praja sesuai dengan tugas pokok dan fungsi serta kewenangannya sebagaimana diatur dalam Peraturan Pemerintah Nomor 32 tentang Pedoman Pembentukan Organisasi Satuan
Polisi Pamong Praja, dan untuk Kota Bandung yang secara eksplisit terlihat pada Peraturan daerah Nomor 04 Tahun 2005 tentang Pembentukan dan Susunan Organisasi Satuan Polisi Pamong Praja Kota Bandung menunjukkan bahwa Satuan Polisi Pamong Praja memberikan pelayanan pemeliharaan ketentraman dan ketertiban umum, tapi pada sisi yang lain juga melaksanakan kewenangan menegakkan peraturan daerah dalam hal ini berposisi sebagai organisasi berkarakter melaksanakan fungsi coersif. Dengan demikian dapat dikatakan bahwa Satuan Polisi Pamong Praja memiliki tipe organisasi pelayanan dan sekaligus tipe organisasi fungsi coersif.

Dalam pelaksanaan tugas dan fungsi Satuan Polisi Pamong Praja Kota Bandung terjadi beberapa peristiwa yang memperlihatkan perilaku kekerasan. Baik perilaku kekerasan yang dilakukan oleh anggota Polisi Pamong Praja maupun kekerasan yang dialami oleh anggota Polisi Pamong Praja. Dari berbagai peristiwa kekerasan dan penyimpangan lain, yang korbannya tidak saja masyarakat tapi juga anggota yang terjadi dalam pelaksanaan tugas Polisi Pamong Praja Kota Bandung, menjadi awal untuk menelusuri budaya organisasi Satuan Polisi Pamong Praja. Beberapa permasalah yang mungkin menjadi pemicu sehingga mengakibatkan peristiwa kekerasan itu muncul, seperti mekanisme kerja penertiban, sikap dan perilaku anggota dalam pelaksanaan tugas, jumlah personil dan struktur organisasi pelaksana operasi penertiban, koordinasi dengan pihak terkait, sarana dan prasarana penunjang pelaksanaan tugas dan lain-lain. 
Memperhatikan fenomena pelaksanaan tugas dan eksistensi polisi pamong praja Kota Bandung, maka menarik untuk dilakukan kajian mendalam budaya organisasi dengan mengamati isi budaya meliputi sistem nilai budaya dan artefak budaya serta mengamati kemampuan adaptasi eksternal lingkungan budayanya dan integrasi internal budayanya dalam memngembangkan budaya yang kaut dan efektif sebagai dalam pelaksanaan tugas dan fungsi sebagai bagian dari organ pemerintahan daerah.

\section{Konsep Budaya Organisasi}

Manusia dan organisasinya selalui diperhadapkan dengan lingkungan yang harus diatasinya, lingkungan diadaptasinya dengan menggunakan bekal hidup yang dimilikinya berupa budi atau akal, dan budaya (culture) sebagai daya budi berupa cipta, rasa dan karsa (Koentjaraningrat dalam Ndraha, 2005: 13). Menurut Tylor (1924: 1), "Culture is that complex whole which includes knowledge, belief, art, morals, law, custome and may other capabilities acquired by man as a member of society". Menurut Carnerio (1968), bahwa budaya adalah : "... is unique human attribute, is something which man interproses between him self and his environment in order to ensure his security and survival. As such, culture is adaptive". Selanjutnya Scermerhorn dan Hunt (1991 : 340) mengemukakan bahwa: "organizational culture is the system of shared beliefs and values that develops within an organization and guides the behavior of its members". Selanjutnya Robbins (1998 : 595-596) mengemukakan bahwa budaya organisasi mengacu ke suatu sistem makna bersama yang dianut oleh anggota-anggota yang membedakan organisasi itu dari organisasi lain.

Menurut Schein (1997) kata budaya menekankan kepada pikiran tentang sesuatu yang dimiliki dan dipegang secara bersama-sama dalam kelompok, ciricirinya meliputi :

1) Keteraturan perilaku yang dapat diamati, seperti bahasa yang digunakan, adat dan tradisi yang berevolusi, ritual-ritual yang diterapkan secara luas dalam variasi situasi yang luas.

2) Norma kelompok berupa standar dan norma seperti dalam ungkapan " a fair day's work for a fair day's pay".

3) Nilai-nilai yang mengikuti, yakni asas-asas dan nilai-nilai terkait dan secara umum diumumkan yang diyakini oleh kelompok untuk dicapai seperti "product quality" atau "price leadership".

4) Filsafat formal: kebijakan dan prinsip-prinsip ideologis yang luas yang memandu perbuatan kelompok terhadap pemegang saham, karyawan, pelanggan dan stakeholder lainnya.

5) Aturan main, yakni aturan yang secara implisit harus dipelajari oleh pendatang baru dalam organisasi "the way ti things oaround here".

6) Situasi perasaan yang dinyatakatan di dalam sebuah kelompok dalam bentuk tata ruang fisik dan cara dalam mana anggota-anggota organisasi berinteraksi satu sama lain, dengan para pelanggan atau dengan pihak lain di luar organisasi.

7) Keterampilan yang mengakar: komponen khusus anggota kelompok yang ditunjukkan dalam melaksankaan tugas tertentu, kemampuan untuk menciptakan sesuatu yang melampaui satu generasi ke generasi lainnya diturunkan tanpa tertulis.

8) Kebiasaan berpikir model mental dan paradigma bahasa, bingkai pengenalan bersama yang memandu persepsi, pemikiran, bahasa yang digunakan anggota-anggota organisasi dan diajarkan kepada anggota-anggota baru dalam sosialisasi dini.

9) Pemahaman bersama pengertian yang timbul yang diciptakan oleh anggota-anggota kelompok pada saat mereka berinteraksi satu sama lain.

Dari serangkaian definisi sebelumnya selanjutnya dapat disimpulkan bahwa Budaya organisasi adalah jiwa organisasi yang berisi seperangkat asumsi, nilai-nilai, norma-norma sebagai sistem keyakinan yang tumbuh dan berkembang dalam organisasi sebagai pandangan, pedoman, landasan tingkah laku bagi anggota-anggotanya agar organisasi mampu melakukan adaptasi eksternal dan integrasi internal untuk tetap eksisnya organisasi.

Budaya organisasi dapat diamati dari lapisan budaya organisasi. Lapisan budaya organisasi pada dasarnya dapat digolongkan menjadi dua, yakni lapisan pada permukaan dan lapisan yang tidak tampak. Lapisan budaya organisasi pada permukaan atau tampak seperti struktur organisasi, pola perilaku anggota organisasi, lambang dan berbagai komponen asesori organisasi. Lapisan yang tidak tampak adalah keyakinan dan nilai yang mendasari dan membentuk perilaku organisasi, termasuk anggota organisasi seperti tujuan, misi dan hakekat pembentukan organisasi.

Menurut Schein (1992: 12) budaya organisasi didefinisikan sebagai :

... a pattern of share basic assumptions that the group learned as its problems of external adaptation and internal integration, that has worked well enough to be considered valid and therefore, to be taught to new members as the corrected way to perceive, think, and feel in relation to those problem...

Budaya organisasi adalah pola asumsi dasar yang ditemukan atau dikembangkan oleh suatu kelompok orang selagi mereka belajar untuk menyelesaikan masalah, menyesuaikan diri dengan lingkungan eksternal, dan berintegrasi dengan lingkungan internal. Asumsi dasar tersebut telah terbukti dapat diterapkan dengan baik untuk menyelesaikan masalah yang dihadapinya dengan sahih. Hal tersebut diajarkan kepada anggota baru sebagai cara yang tepat untuk mempersepsikan, berpikir dan memiliki pemahaman yang kuat dalam hubungan problem tersebut. Selanjutnya Schein (1992:17) melukiskan budaya dalam 3 (tiga) lapisan sebagai mana gambar berikut. 


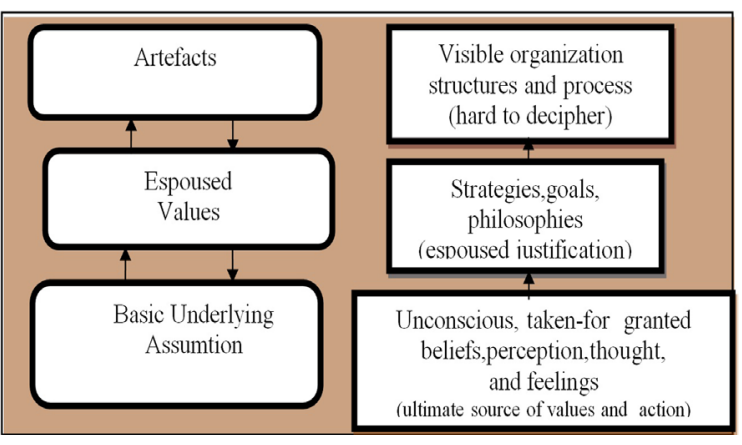

Gambar 1. Model Lapisan Isi Budaya Organisasi (Schein, 1992: 17)

Pengamatan dan pengkajian mendalam terhadap budaya organisasi dapat menggunakan pendekatan yang dilakukan oleh Schein tersebut di atas, bahwa lapisan terdalam dari budaya organisasi adalah anggapan dasar yakni seperangkat keyakinan yang dipelihara dan dipegang teguh dan menjadi landasan dalam bersikap dan berperilaku oleh anggota organisasi, lapisan kedua adalah sistem nilai yang merupakan tujuan-tujuan hidup, philosofi hidup dan nilai-nilai yang dianut anggota organisasi serta lapisan artefak yakni lapisan terluar dari budaya organisasi seperti penampilan fisik, struktur organisasi, standar operasi prosedir, mekanisme kerja dan lain-lain.

\section{METODE}

Metode yang digunakan dalam penelitian ini adalah deskriptif dengan pendekatan kualitatif (qualitative approach) Sebagaimana dikemukakan oleh Geertz (1976: 235, dalam Maxwell, 1996: 4), bahwa "design in qualitative research is an iterative process that involves 'tacking'back and forth between the different components of design the implication of purpose, theory, research questions and methods ...".

Desain penelitian kualitatif dilakukan melalui proses pengulangan (iterative process) yang melibatkan interkasi bolak balik antara beberapa komponen desain yang berbeda dalam rangka menilai implikasi dari : maksud, teori, pertanyaan penelitian, metode dan keabsahan saling mempengaruhi satu sama lain. Pendekatan kualitatif tipe penelitian studi kasus untuk menghasilkan produk penelitian deskriptif yang didesain menurut paradigma kualitatif tidak dimaksudkan untuk menggeneralisir temuan tetapi untuk mempelajari realitas yang kasuistis secara mendalam mengenai budaya organisasi pada satuan polisi pamong praja Kota Bandung.

Pendekatan kualitatif yang menekankan metode epistemologik dalam penelitian ini mampu melahirkan reformulasi dan rekonseptualisasi teori budaya organisasi publik dan kinerja organisasi publik, dari kombinasi antara perspektif yang diteliti dan perspektif peneliti sendiri.

Informan penelitian dimulai dari informan kunci adalah 2 orang anggota polisi pamong pamong praja selanjutnya dalam penelitian ini menetapkan informan antara lain pejabat polisi pamong praja sejumlah 5 orang, anggota polisi pamong praja 10 orang serta para PKL, Gepeng, Tokoh masyarakat sebanyak 10 orang. Teknik pengumpulan data dilakukan dengan teknik observasi (pengamatan) dengan panduan berupa design observation, interviu (wawancara) dengan panduan berupa design interview dan penelaahan dokumen. Analisis data kualitatif dilakukan melalui 3 (tiga) jalur kegiatan yang bersamaan, yakni reduksi data, tampilan atau penyajian data dan penarikan kesimpulan.

\section{HASIL DAN PEMBAHASAN \\ Lapisan Budaya Organisasi Polisi Pamong Praja Kota Bandung}

Budaya organisasi dapat dipahami dari dari 3 (tiga) lapisan budaya organisasi, yakni asumsi dasar sebagai paradigma berpikir anggota organisasi, lapisan nilai budaya organisasi sebagai pedoman bersikap dan bertindak dan lapisan artefak sebagai wujud fisik yang tampak dari budaya organisasi. Budaya organisasi terbentuk seiring dengan sejarah perbentukannya dan peraturan perundangan undangan yang mengaturnya.

Artefak budaya organisasi tampak pada struktur Organisasi, prosedur kerja, aktivitas Utama, unit terpenting uniform dan perlengkapan kerja tergambar sebagaimana diatur dalam Peraturan Daerah Nomor 05 Tahun 2006 tentang Pembentukan organisasi Satuan Polisi Pamong Praja Kota Bandung.

Tabel 1. Artefak Budaya Organisasi Satuan Polisi Pamong Praja Kota Bandung

\begin{tabular}{lll}
\hline No & \multicolumn{1}{c}{ Artefak } & \multicolumn{1}{c}{ Karakteristik } \\
\hline 1 & Tipe Organisasi & $\begin{array}{l}\text { Organisasi Pelayan plus organisasi } \\
\text { penekan }\end{array}$ \\
2 & Struktur Organisasi & Hirarkis/ komando \\
3 & Prosedur Kerja & Mekanistik \\
4 & Aktivitas Utama & Pelayanan,pencegahan dan penindakan \\
5 & Unit Terpenting & Unsur pelaksanayang berhadapan \\
6 & Uniform dan Perlengkapan Kerja & Formalistik \\
7 & Pola Pendekatan Kerja & Persuasif, Koersif \\
\hline
\end{tabular}

Sumber : Diolah dari hasil penelitian Tahun 2009

Lapisan Nilai-nilai organisasi bersumber dari rumusan nilai organisasi sebagaimana termuat dalam buku pedoman anggota polisi pamong praja, nilai budaya setempat yakni budaya "sunda" dan nilai dari nilai budaya lokal (Sunda) serta nilai-nilai yang dikembangkan oleh pimpinan organisasi yang ditanamkan melalui seni beladiri "Tarung Drajat" dengan inti ajaran nilai budaya "mengalahkan dengan menahan diri" yang didasarkan pada prinsip keselarasan otot, otak dan nurani. Dari berbagai sumber dengan rumusan nilai budaya yang berkembang dalam organisasi,maka selanjutnya perlu dilembagakan nilai budaya baru (nbo) dari dengan rumusan nilai utama budaya organisasi yang terdiri dari nilai budaya disiplin, kejujuran, ketegasan, santun, kesetiaan, pengayoman, kesabaran, keselarasan, keadilan, dan kualitas. Sumber nilai budaya organisasi dan pengembangan nilai utama budaya organisasi polisi pamong praja sebagaimana bagan berikut. 
Tabel 2. Nilai-Nilai Yang Membentuk Budaya Organisasi Satuan Polisi Pamong Praja Kota Bandung

\begin{tabular}{|c|c|c|c|}
\hline $\begin{array}{c}\text { Nilai Budaya Sat Pol PP } \\
\text { Kota Bandung Tahun } 2007\end{array}$ & $\begin{array}{c}\text { Nilai Budaya Lokal } \\
\text { (Sunda) }\end{array}$ & $\begin{array}{c}\text { Nilai Budaya } \\
\text { Tarung Derajat }\end{array}$ & $\begin{array}{c}\text { Nilai Budaya Yang } \\
\text { seharusnya } \\
\text { dikembangkan } \\
\end{array}$ \\
\hline 1. Disiplin & 1. Kesetiaan & 1. Kecepatan & 1. Disiplin \\
\hline 2. Kompak & 2. Keadilan & 2. Kekuatan & 2. Kejujuran \\
\hline 3. Bertanggung Jawab & 3. Kejujuran & 3. Keuletan & 3. Ketegasan \\
\hline 1. Berani & 4. Keseimbangan & 4. Keselarasan & 4. Santun \\
\hline 2. Santun & 5. Kebersamaan & $\begin{array}{l}\text { (Dengan inti ajaran } \\
\text { mengindari } \\
\text { kekerasan dan } \\
\text { menghormati hak } \\
\text { dan kewajiban serta } \\
\text { menghargai } \\
\text { persaudaran) }\end{array}$ & 5. Kesetiaan \\
\hline 3. Tegas & 6. Persaudaraan & & 6. Pengayoman \\
\hline 4. Normatif & & & 7. Kesabaran \\
\hline 5. Loyal & & & 8. Keselarasan \\
\hline 6. Tegar & & & 9. Keadilan \\
\hline 7. Sabar. & & & 10. Kualitas \\
\hline
\end{tabular}

Sumber : Diolah dari hasil penelitian Tahun 2009

Satuan Polisi Pamong Praja Kota Bandung sesuai dengan Peraturan Menteri Dalam Negeri Nomor 26 Tahun 2005 Tentang Prosedur Tetap Operasional Satuan Polisi Pamong Praja dalam pelaksanaan tugas dan fungsi menetapkan bahwa nilai budaya organisasi yang menjadi pedoman bertugas antara lain : disipli, kompak, bertanggung jawab, berani, santun, tegas, normatif, loyal, tegar dan sabar. Nilai budaya ini sejalan dengan nilainilai yang tumbuh dan berkembang di lingkungan Satuan Polisi Pamong Praja, seperti nilai budaya yang tumbuh dan berkembang dalam budaya lokal (budaya sunda) antara lain nilai budaya : kesetiaan, keadilan, kejujuran, kebersamaan, persaudaraan. Budaya organisasi pada umumnya diturunkan oleh pemimpinnya, sebagaimana juga polisi pamong praja Kota Bandung, nilai budaya yang tumbuh dan berkembang tidak terlepas dari kepemimpinan Kepala Satuan Polisi Pamong praja Provinsi Jawa Barat yang mengenalkan dan mengajarkan nilai budaya dari perguruan beladiri "Tarung Drajat" yang mana nilai budayanya antara lain : kecepatan, kekuatan, keuletan dan keseimbangan. Inti ajaran ini adalah menghindari menghindari kekerasan dan menghormati hak dan kewajiban serta menghargai persaudaraan. Dari nilai budaya yang berkembang tersebut dengan meramu ketiga sumber nilai budaya, maka nilai budaya yang dikembangkan dan dianut oleh anggota organisasi Satuan Polisi Pamong Praja Kota Bandung, antara lain : Disiplin, Kejujuran, Ketegasan, Santun, Kesetiaan, Pengayoman, Kesabaran, Keselarasan, Keadilan, Kualitas

Asumsi dasar yang membentuk dan menjadi dasar budaya organisasi meliputi dimensi hakikat hubungan dengan lingkungan dimaknai dengan menyelaraskan organisasi dan individu dengan lingkungan organisasi, hakikat kenyataan dan kebenaran bersandar pada realitas sosial dan kebenaran rasional, hakikat waktu, dimaknai sebagai sesuatu yang sangat berharga, hakikat sifat manusia dipahami bahwa sifat manusia baik dan dapat dirubah, hakikat aktifvitas manusia dimaknai untuk selalu menciptakan harmoni, hakikat hubungan manusia mengedepankan kekeluargaan dan kebersamaan, hakikat keseragaman dan keragaman dimaknai dengan rasa persatuan dalam perbedaan.
Karakter budaya dari lapisan asumsi dasar yang dianut oleh organisasi polisi pamong praja digambarkan sebagaimana bagan berikut :

Tabel 3. Karakteristik Asumsi Dasar Budaya Organisasi Satuan Polisi Pamong Praja Kota Bandung

\begin{tabular}{|c|c|c|}
\hline No & Asumsi Dasar & Karakteristik \\
\hline 1 & $\begin{array}{l}\text { Hakikat Hubungan } \\
\text { Dengan Lingkungan }\end{array}$ & $\begin{array}{l}\text { Institusi menyelarasarkan } \\
\text { dengan lingkungan } \\
\text { organisasi }\end{array}$ \\
\hline 2 & $\begin{array}{l}\text { Hakikat Kenyataan dan } \\
\text { Kebenaran }\end{array}$ & $\begin{array}{l}\text { Realitas sosial dan } \\
\text { kebenaran rasional }\end{array}$ \\
\hline 3 & Hakikat Waktu & Waktu sangat berharga \\
\hline 4 & Hakikat Sifat Manusia & $\begin{array}{l}\text { Sifat manusia baik dan } \\
\text { dapat dirubah }\end{array}$ \\
\hline 5 & $\begin{array}{l}\text { Hakikat Aktifvitas } \\
\text { Manusia }\end{array}$ & Harmoni \\
\hline 6 & $\begin{array}{l}\text { Hakikat Hubungan } \\
\text { Manusia }\end{array}$ & $\begin{array}{l}\text { Kekeluargaan dan } \\
\text { kebersamaan }\end{array}$ \\
\hline 7 & $\begin{array}{l}\text { Keseragaman dan } \\
\text { keragaman }\end{array}$ & Kesatuan dalam perbedaan \\
\hline
\end{tabular}

Sumber : Hasil Penelitian Tahun 2009

Lapisan isi budaya organisasi Satuan Polisi Pamong Praja agar semakin kuat dan kondusif, dilakukan melalui aktualisasi nilai-nilai kearifan dan kebijaksanaan dalam budaya lokal terus digali direvitalisasi untuk menjadi nilai organisasi polisi pamong praja. Sikap dan perilaku melayani dan mengayomi disosialisasikan dan dinternalisasikan kepada anggota organisasi dengan keteladanan oleh pimpinan. Kebijakan dan norma Satuan Polisi Pamong Praja yang di atur dalam Peraturan Pemerintah Nomor 32 Tahun 2004 dan Peraturan Menteri Dalam Negeri perlu ditinjau ulang karena memungkinkan terjadinya sengketa kewenangan di lapangan. Kewenangan Satuan Polisi Pamong Praja seperti penanganan unjuk rasa, penjagaan dan pengawalan serta penegakkan Peraturan Daerah berhimpit dengan kewenangan Polisi Negara Republik Indonesia.

Sosok yang dinilai oleh sebagian masyarakat bahwa polisi pamong praja yang militersitik setidaknya terbangun dari dua ketentuan yang menyebabkan pola perilaku dan pendekatan-pendekatan yang dilakukan satpol PP begitu militeristik, pertama terkait dengan pedoman satpol PP sebagaimana diatur dalam PP No. 32 Tahun 2004 tentang Pedoman Satuan Polisi Pamong Praja dan prosedur tetap satpol PP sebagaimana diatur dalam Peraturan Menteri Dalam Negeri Nomor 26 Tahun 2005 Tentang Pedoman Prosedur Tetap Operasional Satuan Polisi Pamong Praja, dan terakhir Peraturan Menteri Dalam NegeriNomor 35 Tahun 2005 Tentang Pedoman Pakaian Dinas, Perlengkapan dan Peralatan Satuan Polisi Pamong Praja.

\section{Adaptasi Eksternal Budaya Organisasi Satuan Polisi Pamong Praja Kota Bandung}

Untuk meningkatkan kemampuan adaptasi eksternal, dilakukan melalui : Peninjauan dan perumusan ulang Rencana Strategis (Renstra), yang meliputi meliputi rumusan visi, misi, strategi, program 
dan kegiatan berdasarkan tuntutan lingkungan; Perumusan tujuan organisasi yang hanya pada penciptaan ketertiban umum dan penegakan Peraturan Daerah tapi juga tujuan organisasi diarahkan pada penciptaan ketentraman umum; Pemenuhan sarana dan prasarana penunjang tugas, antara lain markas komando, mess anggota, kendaraan dinas, pakaian dinas, perlengkapan perorangan yang standar bagi seluruh anggota; Pemerintah Kota Bandung segera menetapkan Peraturan Walikota tentang penjabaran norma dari Peraturan Pemerintah Nomor 34 Tahun 2004, tentang Pedoman Organisasi Satuan Polisi Pamong Praja, Peraturan Menteri Dalam Negeri Nomor 35 Tahun 2005 tentang Pakaian Dinas dan Perlengkapan Satuan Polisi Pamong Praja dan Peraturan Menteri Dalam Negeri Nomor 26 Tahun 2006 tentang Prosedur Tetap Satuan Polisi Pamong; Pengembangan standar operasi prosedur yang dituangkan dalam Peraturan Walikota tentang Standar Pelayanan Publik bidang pelayanan ketentraman dan ketertiban umum oleh Satuan Polisi Pamong Praja.

\section{Integrasi Internal Budaya Organisasi Polisi Pamong Praja Kota Bandung}

Untuk semakin memantapkan integrasi internal, maka dapat dilakukan melalui upaya memupuk korsa dan kebanggaan anggota organisasi sebagai keluarga besar Satuan Polisi Pamong Praja.

Mutasi pegawai dari Satuan Kerja Perangkat Daerah lainnya di lingkungan Pemerintah Kota Bandung menjadi anggota atau pejabat di Satuan Polisi Pamong Praja melalui pertimbangan dan kaidah manajemen kepegawaian berbasiskan karir dan kinerja, sehingga tidak terkesan Satuan Polisi Pamong Praja sebagai tempat pembinaan pegawai yang bermasalah dari Satuan Kerja lain.

Jalur komando dijaga melalui pelimpahan wewenang secara berjenjang, diperjelas kewenangan pada masing-masing unit dan lini yang dituangkan dalam keputusan Kepala Satuan tentang uraian tugas masing-masing unit termasuk kewenangan anggota.

Mengaktifkan pertemuan-pertemuan formal maupun informal seperti rapat mingguan, apel sebelum kerja, outbond untuk memupuk rasa kekeluargaan dan kerjasama; Mengembangkan mekanisme reward and funishment dalam pembinaan personil. Pegawai yang berprestasi diberi penghargaan sebaliknya pegawai yang menyimpang diberi hukuman.

\section{SIMPULAN}

Budaya organisasi Polisi Pamong Praja Kota Bandung pada dimensi artefak budaya organisasi tampak pada struktur Organisasi, prosedur kerja, aktivitas Utama, unit terpenting uniform dan perlengkapan kerja tergambar sebagaimana diatur dalam Peraturan Daerah Nomor 05 Tahun 2006 tentang Pembentukan organisasi Satuan Polisi Pamong Praja Kota Bandung. Lapisan nilai budaya organisasi bersumber dari rumusan nilai organisasi dan nilai budaya setempat yakni budaya "sunda" dan nilai dari nilai budaya lokal (Sunda) serta nilai-nilai yang dikembangkan oleh pimpinan organisasi yang ditanamkan melalui seni beladiri "Tarung Drajat" dengan inti ajaran nilai budaya "mengalahkan dengan menahan diri" yang didasarkan pada prinsip keselarasan otot, otak dan nurani. Selanjutnya perlu dilembagakan nilai budaya baru (nbo) dari dengan rumusan nilai utama budaya organisasi yang terdiri dari nilai budaya disiplin, kejujuran, ketegasan, santun, kesetiaan, pengayoman, kesabaran, keselarasan, keadilan, dan kualitas.

Budaya organisasi Satuan Polisi Pamong Praja menjadi kuat dan kondusif dilakukan melalui penguatan adaptasi eksternal dan integrasi internal. Penguatan adaptasi eksternal dilakukan melalui perumusan ulang visi dan misi organisasi, penetapan tujuan dan strategi organisasi, pembaharuan sarana prasarana, pengembangan pengukuran kinerja dan upaya perbaikan yang disesuaikan dengan tuntutan lingkungan. Penguatan Integrasi internal budaya dilakukan melalui penciptaan bahasa bersama, terbangunnya batasan kelompok untuk memperkuat korsa, penetapan status dan kewenangan melalui pendelegasian kewenangan, penataan hubungan dalam kelompok melalui hubungan saling percaya antar anggota organisasi, pemberian penghargaan dan hukuman secara berimbang dengan mengembankan sistem insentif bagi yang berprestasi dan sistem hukuman kepada anggota yang melakukan pelanggaran.

\section{DAFTAR PUSTAKA}

Alvesson, Mats. 2002. Understanding Organizational Culture. London: Sage Publications.

Brown, Andrew. 1998. Organization Culture. Second edition. New York: Prentice Hall.

Carneiro, Robert L. 1968. Cultural Adaptation., dalam Sills, David L. (ed.), International Encyclopedia of The Sosial Sciences, Volume 3 and 4. New York: The Macmillan Company \& The Free Press.

Drucker, Peter. 1993. Managing For The Future, The 1990s and Beyond. New York: Truman Talley.

Dwiyanto, Agus. 2006. Mewujudkan Good Governance Melalui Pelayanan Publik. Yogyakarta: Japan International Cooperation Agency \& Universitas Gadjah Mada Press.

Frederickson, H. 1984. Administrasi Negara Baru, Jakarta: LP3ES.

Garna, Judistira. 1998. Budaya Usaha dan Perusahaan, Business and Corporate Culture. Bandung: PPS Unpad.

Gibson, J.L. \& J.M. Ivancevich, and J.H. Donnely. 2003. Organizations : Behavior, Structure, Processes. Ninth Edition. New York: Irwin Port.

Bachtiar W. Harsya. 1994. Ilmu Kepolisian: suatu cabang ilmu yang baru.. Gramedia. Jakarta.

Henry, Nicholas. 1995. Publik Administrator and Public Affairs. Sixth Edition. Englewood Cliffs, New York: Prentice Hall. 
Hofstede, Geert. 1980. Culture's Consequences International Differences in Work-rlated Values. Beverly Hills: SAGA.

Fukuyama, Francis. 2005. Memperkuat Negara : Tata Pemerintahan dan Tata Dunia Abad 21, Jakarta : Gramedia Pustaka Utama.

Ibrahim, Amin. 2005. Perilaku Organisasi. Bandung: PPS Unpad

2008. Pokok-Pokok Administrasi Publik dan Implementasinya. Refika Aditama Bandung.

Kotter, P., Jhon and Heskettt, L. James. 1992. Corporate Culture and Performance. New York: Maxwell MacMillan.

Kumorotomo, Wahyudi. 2002. Etika Administrasi Negara. Jakarta: Raja Grafindo

Mangkunegara, Anwar Prabu, A.A. 2005. Perilaku Dan Budaya Organisais. Bandung: Refika Aditama.

Moeljono, Djokosantoso. 2003. Budaya Korporat dan Keunggulan Korporasi. Jakarta: Elex Media Komputindo.

Ndraha, Taliziduhu. 1997, Budaya Organisasi, Jakarta: Rineka Cipta.

Oudang, M. 1952. Perkembangan Kepolisian Di Indonesia. Mahabarata. Jakarta.

Robbins, Stephen P. 1990. Organization Theory. New York: Prentice Hall Inc. Englewood Cliffs.

Sackmann, Sonja. A. 1991. Cultural Knowledge in Organizations, Exploring the Collective Mind. New York: Sage Publication.

Saefullah, H.A. Djadja, 2007. Pemikiran Kontemporer Administrasi Publik: Perspektif Manajemen Sumber Daya Manusia Dalam Era Desentralisasi, Bandung: LP3AN Fisip Unpad.

Santoso, Priyo Budi. 1995. Birokrasi Pemerintahan Orde Baru. Jakarta: Raja Grafindo.

Sathe, Vijay. 1985. Culture and Related Corporate Realities. New York: Richard D Irwin, Inc. Homewood, III.

Schein, Edgar H. 1992. Organizational Culture and Leadership. San Francisco: Jossey-Bas, Publ.
Senge, Peter M. 1990, The Fifth Discipline, Double Day Currency. London: Nicholas Brealey Publishing.

Susanto. A.B. 1997. Budaya Perusahaan. Jakarta: Elex Media Komputindo.

Tan, Victor, S.L. 2202. Changing Your Corporate Culture, Singapore: Times Books International.

Wibowo. 2006, Manajemen Perubahan, edisi kedua, Jakarta : Raja Grafindo Persada.

Wasistiono, dkk., 2009. Model Organisasi dan Pengukuran Jabatan Fungsional Satuan Polisi Pamong Praja, Penelitian Kelompok, Jakarta, PPS MAPD IPDN

\section{Peraturan Perundang-Undangan}

Undang- undang 32 Tahun 2004 tentang Pemerintahan Daerah.

Peraturan Pemerintah Nomor 32 Tahun 2004 Tentang Pedoman Organisasi Satuan Polisis Pamong Praja.

Peraturan Pemerintah Nomor 41 Tahun 2007 Tentang Pedoman Penyusunan Perangkat Daerah.

Peraturan Daerah Kota Bandung Nomor 04 Tahun 2005 Tentang Pembentukan dan Susunan Organisasi Satuan Polisi Pamong Praja Kota Bandung.

Peraturan Daerah Kota Bandung Nomor 12 Tahun 2005 Tentang Ketertiban, Kebersihan dan Keindahan.

Peraturan Presiden Republik Indoneia Nomor 7 Tahun 2005 Tentang Rencana Pembangunan Jangka Menengah Nasional (RPJMN) 2004-2009. 2005 Jakarta: Sinar Grafika

Peraturan Menteri Dalam Negeri Nomor 26 Tahun 2005 Tentang Pedoman Prosedur Tetap Operasionalsatuan Polisi Pamong Praja.

Peraturan Menteri Dalam Negeri Nomor 35 Tahun 2005 Tentang Pedoman Pakaian Dinas, Perlengkapan Dan Peralatan Satuan Polisi Pamong Praja. 